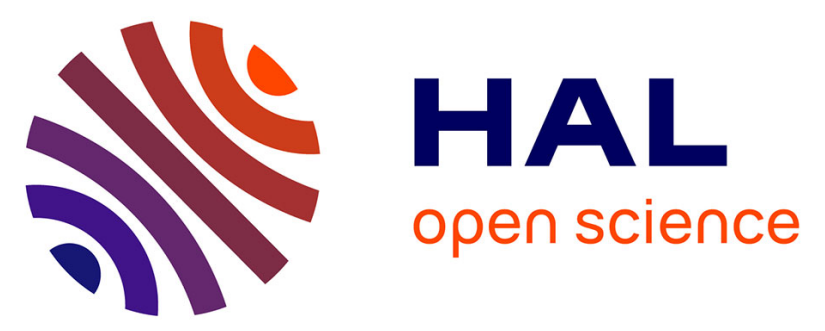

\title{
Release of alpha-tocopherol from antioxidative low density polyethylene film into fatty food simulant: Influence of complexation in beta-cyclodextrin
}

István Siró, Éva Fenyvesi, Lajos Szente, Bruno de Meulenaer, Frank

Devlieghere, Judit Orgoványi, Judit Sényi, József Barta

\section{To cite this version:}

István Siró, Éva Fenyvesi, Lajos Szente, Bruno de Meulenaer, Frank Devlieghere, et al.. Release of alpha-tocopherol from antioxidative low density polyethylene film into fatty food simulant: Influence of complexation in beta-cyclodextrin. Food Additives and Contaminants, 2006, 23 (08), pp.845-853. 10.1080/02652030600699064 . hal-00577478

\section{HAL Id: hal-00577478 \\ https://hal.science/hal-00577478}

Submitted on 17 Mar 2011

HAL is a multi-disciplinary open access archive for the deposit and dissemination of scientific research documents, whether they are published or not. The documents may come from teaching and research institutions in France or abroad, or from public or private research centers.
L'archive ouverte pluridisciplinaire HAL, est destinée au dépôt et à la diffusion de documents scientifiques de niveau recherche, publiés ou non, émanant des établissements d'enseignement et de recherche français ou étrangers, des laboratoires publics ou privés. 


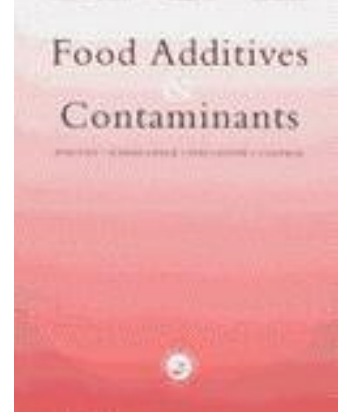

Release of alpha-tocopherol from antioxidative low density polyethylene film into fatty food simulant: Influence of complexation in betacyclodextrin

\begin{tabular}{|r|l|}
\hline Journal: & Food Additives and Contaminants \\
\hline Manuscript ID: & TFAC-2005-409.R1 \\
\hline Manuscript Type: & Original Research Paper \\
\hline Methods/Techniques: & Chromatography - HPLC \\
\hline Additives/Contaminants: & $\begin{array}{l}\text { Packaging - food simulants, Antioxidants, Packaging - migration } \\
\text { modelling, Packaging active packaging }\end{array}$ \\
\hline Food Types: & Cereals, Oils and fats \\
\hline \multicolumn{2}{|r}{} \\
\hline
\end{tabular}




\section{Release of alpha-tocopherol from antioxidative low density}

2 polyethylene film into fatty food simulant: Influence of complexation

\section{3 with beta-cyclodextrin}

4

5

6

7 Sényi $^{1}$ and J. Barta ${ }^{1}$

8

$9{ }^{1}$ Corvinus University of Budapest, Faculty of Food Science, Department of 10 Preservation, Ménesi út 45, 1118 Budapest, Hungary

$11{ }^{2}$ Cyclolab, Cyclodextrin Research and Development Laboratory Ltd., Illatos út. 7., 1097

12 Budapest, Hungary

$13{ }^{3}$ Ghent University, Department of Food Safety and Food Quality, Coupure Links 653,

149000 Ghent, Belgium

$15{ }^{4}$ Eötvös Loránd University of Budapest, Faculty of Science, Department of Chemical

16 Technology and Environmental Chemistry, Pázmány Péter sétány 1/A, 1117 Budapest,

17 Hungary

18

19

20

21

$22 *$ To whom correspondence should be addressed

23

E-mail: istvan.siro@uni-corvinus.hu 


\section{Abstract}

25

26 The release of alpha-tocopherol from two formulations (with and without complexation

27 with beta-cyclodextrin) of low density polyethylene (LDPE) film was examined.

28 Specific migration studies were performed at $7.0 \pm 0.5^{\circ} \mathrm{C}$ using plastic bags filled with

$2995 \%$ ethanol as fatty food simulant. The amount of complexed and free (non-

30 complexed) alpha-tocopherol migrating into the food simulant was followed by a high

31 performance liquid chromatography (HPLC). It was concluded that complexation with

32 beta-cyclodextrin had a significant effect on the release rate of the antioxidant. Using a

33 mathematical model for the description of the migration, a decrease in diffusion 34 coefficient (D) of one order of magnitude was calculated in the case of complexed

35 alpha-tocopherol compared to the free form. Total migration of alpha-tocopherol from 36 both films was observed, meaning that the partition coefficient of tocopherol was not

37 influenced by the incorporation with cyclodextrin. Thus, complexation might be the key

38 to a long lasting antioxidative effect of such kind of active packaging.

40 Keywords: active packaging, alpha-tocopherol, antioxidants, beta-cyclodextrin, 41 controlled release, diffusion coefficient; 
43

44

45

46

47

\section{Introduction}

To prevent or retard any deterioration in quality of packaged foods, active packaging including the concept of the controlled release of active components to foodstuffs has shown the greatest potential to improve storage stability (Miltz et al. 1995, Vermeiren et al. 1999, Appendini \& Hotchkiss 2002, LaCoste et al. 2005). The motivation for developing controlled release packaging is to transfer the active agent from the polymeric carrier to the surface of the food in order to maintain a predetermined concentration and thus to prolong the shelf-life without adding excess additives directly to food products. This transfer of the active agent is a result of the diffusion in the polymer matrix and the partition process between the polymer and the food surface. The diffusion is described by the diffusion coefficient (D), while the partition is characterised by the partition coefficient (K) (Garde et al. 2001, Helmroth et al. 2002, Hernandez-Muñoz et al. 2002).

Controlled release of drug delivery has been used for some time (Colombo et al. 1996, Kuijpers et al. 1998, Bezemer et al. 2000), and procedures for achieving release under various conditions are well-established. However, considerable research on testing the concept of controlled release of active compounds from food packaging did not appear until the last decade (Floros et al. 2000). The promulgation of EC regulation 1935/2004 on materials and articles intended to come into contact with food may facilitate the development of controlled release packaging concepts (EC 2004). This regulation states that, unlike traditional packaging materials and articles, active packaging concepts are not inert by their design. They are designed to deliberately incorporate 'active' 
67 components intended to be released into the food or to absorb substances from the food, therefore they may change the composition or the organoleptic properties of the food.

69 These changes, however, always should comply with the Community provisions 70 applicable to food, such as the provisions of Directive 89/107/EEC on food additives. In 71 particular, substances such as food additives deliberately incorporated into certain active 72 food contact materials and articles for release into packaged foods or the environment surrounding such foods, should be authorised under the relevant Community provisions.

74 Besides the main requirements of use established in EC regulation 1935/2004, further regulations should be addressed in specific measures, to include positive lists of authorised substances and/or materials and articles, which should be adopted as soon as possible.

Antioxidant packaging is a promising type of controlled release concepts, in which antioxidants are incorporated into or coated onto food packaging materials to reduce oxidation in the packed food (Vermeiren et al. 1999, LaCoste et al. 2005). For example, incorporation of synthetic antioxidant compounds, such as butylated hydroxytoluene (BHT) and butylated hydroxyanisole (BHA) in high-density polyethylene has been shown to protect cereals from oxidation (Miltz et al. 1987, Wessling et al. 2000a). In recent years, however, there has been a growing interest in the use of natural antioxidants such as tocopherols in food packaging applications, because of an emerging concern regarding long-term safety and negative consumer perception of synthetic antioxidants ( $\mathrm{Yu}$ et al. 2002, Maisuthisakul et al. 2006). For example, BHA and BHT have been suspected of being responsible for liver damage and carcinogenesis 
91 compounds with a positive public perception, broad regulatory approvals, and environmentally friendly appeal to the consumers (Wessling et al. 2000b, LaCoste et al. 2005). Besides being an effective antioxidant for reducing oxidation in foods, tocopherols are also excellent stabilizers for polymer processing (Al-Malaika et al. 1994, Billingham and Garcia-Trabajo 1995, Al-Malaika et al. 1999, 2001a, 2001b). Therefore, tocopherols can serve dual functions when added to packaging: as a stabilizer for polymer processing and as an antioxidant in controlled release to reduce oxidation (LaCoste et al. 2005).

100 The release of alpha-tocopherol from packaging material depends on several factors.

101 Wessling et al. (1999) revealed that the retention of alpha-tocopherol is influenced by the type of the polymer as well as the fat, alcohol and organic acid content of the food product (Wessling et al 2000c). Heirlings et al. (2004), however, found that the polarity of the polymer matrix had only a slight effect on the migration rate of alpha-tocopherol.

105 In this latter study the antioxidant was also adsorbed onto silica materials in order to

106 give a protection during extrusion and to ensure a controlled release. By this way 107 antioxidant release could be elongated for about three-four days at $7^{\circ} \mathrm{C}$. For some food 108 applications, however, an even slower antioxidant release would be desired.

110 Recently there has been an increasing interest in the use of cyclodextrins as a tool for 111 controlled release of active compounds due to their outstanding ability to form 112 molecular complexes with hydrophobic guest molecules. Cyclodextrins (CD) are

113 obtained by degradation of starch. They are cyclic oligosaccharides consisting of six 114 (alpha-CD), seven (beta-CD) or eight (gamma-CD) glucopyranose units, which are 
115 bound together by alpha (1-4)-linkages forming a torus-shaped ring structure. Due to

116 their polar hydrophilic outer shell and relatively hydrophobic cavity, they are able to

117 build up host-guest complexes by inclusion of suitable hydrophobic molecules (e.g.

118 alpha-tocopherol). The formation of these complexes leads to significant changes of the

119 solubility and reactivity of the guest molecules, but without any chemical modification

120 (Szejtli 1996).

121

122 In this study the influence of complexation by beta-cyclodextrin on the migration of

123 alpha-tocopherol from LDPE was investigated. The migration of alpha-tocopherol both

124 complexed in beta-cyclodextrin and non-complexed from Low Density Polyethylene

125 (LDPE) polymer into a fatty food simulant was followed at $7.0 \pm 0.5^{\circ} \mathrm{C}$. A migration

126 model suggested by Hamdani et al. (1997) and Piringer (2000) was fitted to the

127 migration profiles and diffusion coefficients were calculated. Besides protecting the

128 antioxidant against high temperature during extrusion, beta-cyclodextrin is also

129 expected to slow down the release of alpha-tocopherol from LDPE thus ensuring a

130 longer lasting antioxidative effect.

131 


\section{Materials and methods}

132

\section{Complexation process in beta-cyclodextrin}

Pharma-grade beta-CD (Wacker Chemie, Germany, Lot No. 70T179, 227 g, 0.17 mol)

was suspended in $700 \mathrm{~mL}$ distilled water by stirring at ambient temperature. Technical

137 grade alpha-tocopherol [Irganox ${ }^{\circledR}$ E201=3,4-Dihydro-2,5,7,8-tetramethyl-2-(4,8,12-

138 trimethyltridecyl)-2H-1-benzopyran-6-ol] (Ciba Specialty Chemicals, Basel,

139 Switzerland) (43.06 g, $0.1 \mathrm{~mol}$ ) dissolved in $50 \mathrm{~mL} \mathrm{96 \%} \mathrm{ethanol} \mathrm{(analytical} \mathrm{reagent}$

140 grade, Merck, Darmstadt, Germany) was added to the aqueous suspension by

141 continuous stirring. The stirring was continued for $0.5 \mathrm{~h}$ at $60 \mathrm{C}$ and for $8 \mathrm{~h}$ at ambient

142 temperature, then the suspension was left to stay in the refrigerator for approximately 16

143 hours. The next day it was filtered and the filtrate was dried for 2 days at room

144 temperature in vacuum exsiccator beside phosphorus pentoxide till constant weight. The 145 complex obtained (214 g) contained $15.5 \%$ alpha-tocopherol as measured by the

146 following method. $25.0 \mathrm{mg}$ complex was dissolved in $25.0 \mathrm{ml}$ water-ethanol $(1: 1)$

147 mixture and the absorbance was measured at $292 \mathrm{~nm}$ by a HP 8452 UV-VIS diode array

148 spectrophotometer (Hewlett-Packard Co., Palo Alto, CA, USA).

Heat stability measurements

151

152

153

154

155

The heat stability of free and complexed alpha-tocopherol was characterized by thermogravimetric analysis (TGA) as suggested by Ferdinando et al. (2001). A MOM Derivatograph PC (MOM, Hungary) was used to obtain differential thermo-gravimetric (DTG) curves. Experiments were carried out on 15-20 mg of sample in aluminum-oxide 
156 open pan at a heating rate of $5{ }^{\circ} \mathrm{C} \min ^{-1}$, under pure nitrogen at a flow rate of $40 \mathrm{~mL}$

$157 \mathrm{~min}^{-1}$. Samples were heated up to $250^{\circ} \mathrm{C}$.

158

Preparation of packaging materials

160

161 The experiments were carried out using Low Density Polyethylene (LDPE, Lot No. FB

162 243-51) polymer provided by Tiszai Vegyi Kombinát (Tiszaújváros, Hungary). Two

163 types of film were prepared: film A contained free alpha-tocopherol while film B

164 comprised this antioxidant complexed into beta-cyclodextrin. The antioxidant alpha-

165 tocopherol, free and complexed was mixed with the LDPE granulates at a nominal

166 concentration of $2000 \mathrm{mg} \mathrm{kg}^{-1}$ by a simple scroll extruder, and the granulates were

167 transformed into films on a blown film line (Kuhne K36, Kuhne GmbH, Germany).

168 Besides alpha-tocopherol (Irganox ${ }^{\circledR}$ E201) the films contained no further antioxidants.

169 The thicknesses of film A and film B, measured by a micrometer (Mitutoyo, Mitutoyo

170 Corporation, Japan), were approximately $60 \mu \mathrm{m}$ and $50 \mu \mathrm{m}$, respectively.

Determination of the initial alpha-tocopherol concentrations

173

174 The exact initial alpha-tocopherol content of the polymer was determined prior to the

175 migration experiment using the procedure described by Heirlings et at. (2004) with

176 some slight modifications. Briefly, $1.0 \mathrm{~g}$ film was weighed and cut into small pieces

177 (approximately $10 \mathrm{~mm} \times 10 \mathrm{~mm}$ ) then dissolved in $70 \mathrm{~mL}$ toluene (analytical reagent

178 grade, Reanal, Budapest, Hungary). During the dissolving process the solution was

179 heated up to $65^{\circ} \mathrm{C}$ and stirred by a magnetic stirrer (MLW RH3, VEB MLW, Freital,

180 Germany). After 15 minutes, $50 \mathrm{~mL}$ cold methanol (analytical reagent grade, Reanal, 
181 Budapest, Hungary) was added in order to precipitate the polymer. Afterwards the

182 solution was filtered through a paper filter (Macherey-Nagel GmbH, $614^{1 / 4} \varnothing 150 \mathrm{~mm}$,

183 Düren, Germany). The solvents were evaporated to dryness in a rotary evaporator

184 (Heidolph VV2000, Heidolph Elektro GmbH \& CO KG, Kelheim, Germany) at 50 $\mathrm{C}$.

185 The residue was resolved in $5 \mathrm{~mL}$ methanol of HPLC grade (Reanal, Budapest,

186 Hungary). After filtering through a Nyfalo $^{\circledR}$ Z269514 syringe filter (Sigma-Aldrich

187 Chemie GmbH, Steinheim, Germany), the samples were analysed by a high

188 performance liquid chromatography (HPLC) system described under.

189

190 High performance liquid chromatographic analysis

191

194

197

198

199

200

201

202

203 204

A Shimadzu HPLC system was used (Shimadzu Corporation, Kyoto, Japan), which consisted of a Shimadzu LC-10AD solvent delivery pump and a Shimadzu SPD-10A UV-VIS detector. Samples were injected manually through a Model 7725i injection valve with a $20 \mu \mathrm{L}$ sample loop (Rheodyne, Cotati, CA, USA). A Discovery C18 (250 x $4.6 \mathrm{~mm}, 5 \mu \mathrm{m})$ column equipped with a Supelguard ${ }^{\circledR}$ guard column $(20 \times 4.0 \mathrm{~mm}, 5 \mu \mathrm{m})$ (Supelco, Bellefonte, PA, USA) was used. Elution with a flow rate of $1.0 \mathrm{~mL} \mathrm{~min}^{-1}$ was monitored by UV detection at $292 \mathrm{~nm}$. 100\% HPLC methanol was used as mobile phase. The injection volume was $20 \mu \mathrm{l}$ and total analysis time was set at 13 minutes. Data acquisition and processing were accomplished with a workstation using Class-VP 4.3 software (Shimadzu). Alpha-tocopherol was identified by matching of its retention time with the corresponding peak in the standard solution. Quantification was carried out by the integration of the peak areas and external calibration. 
205 The linearity of the determination method was measured by injecting alpha-tocopherol

206 solutions of different concentrations (100, 250, 500, 750 and $\left.1000 \mathrm{mg} \mathrm{L}^{-1}\right)$. Then the

207 peak areas were calculated and were expressed as a function of the concentration. The

208 response was linear within the examined range with a correlation coefficient of 0.9996.

210 Repeatability and recovery of the HPLC analysis were evaluated by analysing five

211 replicates of 50, 250, 750 and $1000 \mathrm{mg} \mathrm{L}^{-1}$ of alpha-tocopherol standard solutions. The

212 obtained relative standard deviations (RSD) were between $0.7-1.2 \%$ and the recovery

213 found to be $95.8-106.0 \%$.

214

215 Specific migration studies

216 Migration profiles of alpha-tocopherol from the two kinds of film were investigated

217 using bags filled with food simulant. The experimental set was based on the migration 218 study of Heirlings et al. (2004). As food simulant 95\% ethanol (analytical reagent grade,

219 Reanal, Budapest, Hungary) was used instead of the normally proposed olive oil in 220 order to avoid the difficulties associated with the sample preparation of oil and the 221 quantification problems arising from the originally high alpha-tocopherol content of 222 olive oil.

224 The migration bags with a size of $0.1 \mathrm{~m} \times 0.1 \mathrm{~m}$ were filled entirely with $100 \mathrm{~mL} 95 \%$ 225 ethanol $(<1 \mathrm{~mL}$ air/bag). The weight of the empty bags was approximately $1.2 \mathrm{~g}$ and $2261.0 \mathrm{~g}$ for film A and film B, respectively. After filling the bags, they were heat-sealed 227 (Model N200, Cromat ${ }^{\circledR}$, Zagreb, Croatia) and stored at $7.0 \pm 0.5{ }^{\circ} \mathrm{C}$ in a refrigerator 228 with forced ventilation for 65 and 145 days in case of film A and film B, respectively. 
229 In order to provide the proper contact area and time for both sides of the bag, they were 230 turned daily.

231

232 To determine the amount of alpha-tocopherol migrated in the food simulant, the whole 233 amount of food simulant ( $95 \%$ ethanol) was evaporated to dryness in a rotary 234 evaporator at $50^{\circ} \mathrm{C}$ and the residue was resolved in 1.0-5.0 mL methanol of HPLC 235 grade, then the samples were filtered and injected into the chromatographic system. The 236 concentration of alpha-tocopherol was determined by the HPLC method described 237 above. In each time of measurements three bags of film A and B were analysed. 238 Samples were analysed once or twice a day at the beginning of the migration 239 experiment and less frequently as the migration process was nearing the equilibrium. In 240 total 72 and 90 bags of film A and film B were analysed, respectively. All prepared 241 samples were injected at least duplicate. Mean values and standard deviations were 242 calculated by Microsoft ${ }^{\circledR}$ Excel 2000 (Microsoft Corporation, USA ).

244 Migration modelling

246 A migration process was fully described by the kinetics of migrant diffusion in each

247 phase (expressed by the diffusion coefficient, D) and the chemical equilibrium 248 (expressed by the partition coefficient, K). The partition coefficient of a migrating 249 compound between the polymer and the food was defined as follows:

$250 \quad K_{P / F}=\frac{c_{P, \infty}}{c_{F, \infty}}$

251 where $\mathrm{c}_{\mathrm{P}, \infty}\left(\mathrm{mg} \mathrm{kg}^{-1}\right)$ and $\mathrm{c}_{\mathrm{F}, \infty}\left(\mathrm{mg} \mathrm{kg}^{-1}\right)$ are the equilibrium concentrations of the 252 component in the polymer and the food, respectively. 
254 The apparent diffusion coefficient (D) of alpha-tocopherol was determined from the

255 migration versus time data, which was fitted to Fick's second law for an infinite slab in 256 contact with an infinite volume of solvent (Crank 1975):

257

$$
\frac{M_{F, t}}{M_{F, \infty}}=1-\sum_{n=0}^{\infty} \frac{8}{(2 n+1)^{2} \pi^{2}} \exp \left[-\frac{(2 n+1)^{2} \pi^{2}}{4 d_{P}{ }^{2}} D t\right]
$$

258 where $\mathrm{M}_{\mathrm{F}, \mathrm{t}}(\mathrm{mg})$ is the amount of the migrant in the food at particular time $\mathrm{t} ; \mathrm{M}_{\mathrm{F}, \infty}(\mathrm{mg})$

259 is the amount of the migrant in the food at equilibrium; $d_{P}(\mathrm{~cm})$ is the thickness of the

260 polymer; $\mathrm{D}\left(\mathrm{cm}^{2} \mathrm{~s}^{-1}\right)$ is the diffusion coefficient of the migrant in the polymer and $\mathrm{t}(\mathrm{s})$ is

261 the contact time.

262

263 The diffusion coefficient (D) was determined by minimising the sum of squares in

264 errors (SSE) between the estimated and measured values.

\section{Results and discussion}

267 Influence of the complexation process on heat stability

268 During extrusion, granulates and polymer additives are exposed to relatively high 269 temperatures, often reaching $200 \pm 30^{\circ} \mathrm{C}$ depending on the type of polymers. Therefore, 270 polymer additives should be stable up to this temperature range.

272 Cyclodextrins are often used to increase heat stability of several compounds. In our experiment the effect of complexation on the heat stability of alpha-tocopherol was also assessed. In Figure 1 the differential thermo-gravimetric (DTG) curve of alphatocopherol/beta-cyclodextrin complex is compared to the DTG curves of the free 
276 components (alpha-tocopherol and beta-cyclodextrin). It can be seen that the DTG curve 277 of alpha-tocopherol was flat between 50 and $190^{\circ} \mathrm{C}$, which means that it is stable until $278190^{\circ} \mathrm{C}$. It started decomposition at $191^{\circ} \mathrm{C}$. The DTG curve of beta-cyclodextrin showed 279 a single peak between 38 and $127^{\circ} \mathrm{C}$ (with $90^{\circ} \mathrm{C}$ peak temperature). This stage is related 280 to the dehydration with $12.7 \%$ of water weight loss. Up to $250^{\circ} \mathrm{C}$ no evidence of 281 decomposition were experienced. This corresponds to the information found in the 282 literature, which stated that decomposition of cyclodextrins occurs only at around 300 ${ }^{\circ} \mathrm{C}$ (Hedges et al. 1995).

285 The solid line in Figure 1 represents the DTG curve of alpha-tocopherol/beta286 cyclodextrin complex. Only one stage appeared on the curve between 35 and $138^{\circ} \mathrm{C}$. 287 This peak corresponds to the water loss process. The DTG peak minimum temperature was $87^{\circ} \mathrm{C}$ with $7.8 \%$ of water weight loss. After this peak no further weight loss was 289 detected until $197^{\circ} \mathrm{C}$, when the decomposition of the complex started. "[insert Figure 1 about here]"

Heat stability measurements indicated that both the free alpha-tocopherol and the alphatocopherol/beta-cyclodextrin complex are stable up to $190^{\circ} \mathrm{C}$. The complexation process

294 did not increase the heat stability of alpha-tocopherol significantly, however, alpha295 tocopherol is anyway quite heat stable.

297 Initial alpha-tocopherol concentrations in the films

298 The exact alpha-tocopherol content of the films was determined by HPLC-UV at the 299 beginning of the migration experiment. Ten replicate analyses were performed for both 
300 film A (free alpha-tocopherol) and film B (complexed alpha-tocopherol). The recovery

301 of the analyses, determined by subjecting solutions containing $2000 \mathrm{mg} \mathrm{L}^{-1}$ alpha-

302 tocopherol in methanol to the dissolving, filtering and evaporation procedure, was 80.6

$303 \pm 4 \%$. Alpha-tocopherol concentrations in film A and B found to be $1621 \pm 107 \mathrm{mg} \mathrm{kg}^{-1}$

304 and $1500 \pm 322 \mathrm{mg} \mathrm{kg}^{-1}$, respectively. It is assumed that a significant part of the

305 originally added alpha-tocopherol $\left(2000 \mathrm{mg} \mathrm{kg}^{-1}\right)$ was lost during manufacturing of the

306 film, which was experienced also by other authors. For example Wessling et al. (2000b)

307 found that approximately $66 \%$ of the originally added alpha-tocopherol was lost during

308 LDPE film processing. Heirlings et al. (2004), however, found lower loss of alpha-

309 tocopherol in LDPE films after processing but this was explained by the presence of

310 other types of antioxidant in the polymer besides alpha-tocopherol. When analysing the

311 initial alpha-tocopherol concentration in film B, rather high relative standard deviation

$312(21.5 \%)$ was found. This was probably due to the inhomogeneous distribution of the

313 complexes in the film, which was even visible. Because of the relatively polar nature of

314 the outer shell of cyclodextrin molecules, it is fairly difficult to distribute them in the

315 apolar LDPE matrix. Further problems occurred due to the development of CD

316 agglomerates, resulting in unfavourable optical characteristic of the film: visible white

317 spots in the LDPE matrix.

319 Specific migration experiments

320 The migration of an additive from the packaging material into the food simulant can be

321 followed by determination of its concentration either in the polymer or in the food

322 simulant. This former method, however, suffers from a substantial disadvantage:

323 namely, that the extraction of the analyte from the polymer matrix is often quite difficult 
324 and time-consuming. Therefore in the present study the migration process was followed 325 by determining the amount of alpha-tocopherol migrated into the food simulant at 7.0 $326 \pm 0.5^{\circ} \mathrm{C}$ as a function of time. Progress of migration was expressed as the ratio of the 327 migrated amount of alpha-tocopherol in a particular time and at equilibrium $\left(\mathrm{M}_{\mathrm{F}, \mathrm{t}} /\right.$ $\left.328 \mathrm{M}_{\mathrm{F}, \infty}\right)$.

330 The migration profiles of film A and B are compared in Figure 2. As it can be seen in 331 the figure, a significant difference in the rate of migration was found between film A and film B. As alpha-tocopherol is fat soluble fast migration from LDPE into ethanol was expected. In case of film A containing alpha-tocopherol in free (non-complexed)

334 form this assumption was verified. As can be seen in Figure 2, in about 400 hours 335 approximately $85 \%$ of the total amount of alpha-tocopherol had migrated from film A to 336 the fatty food simulant. In the first two weeks, migration showed an exponential increase and reached an equilibrium in the following weeks, similarly to previous experiments reported by Heirlings et al. (2004). Considering real food packaging applications, this practically means, that the high initial rate of release of antioxidant

340 could inhibit the initiation step of oxidation taking place at the early stage of the

341 storage. It can result in a high antioxidant concentration at the food surface and hence in 342 increased diffusion rate from the surface into the bulk food due to the high concentration.

345 Film B contained alpha-tocopherol complexed into beta-cyclodextrin with the aim to

346 protect the antioxidant during film production on one hand, and to ensure slower, but

347 sufficient release to the food simulant on the other hand. Migration profile of alpha- 
348 tocopherol released from film B into the food simulant is showed also in Figure 2. It can

349 be concluded, that $85 \%$ of the total amount of alpha-tocopherol at equilibrium had

350 migrated in 2324 hours from the polymer to the food simulant, while total migration

351 was reached in about 3500 hours. This means that the migration rate of alpha-

352 tocopherol from film B is significantly lower than that of film A.

353

354

355

356 The initial amount of alpha-tocopherol in the bags can be calculated as follows. In the

362 At equilibrium approximately $1.95 \mathrm{mg}$ and $1.48 \mathrm{mg}$ alpha-tocopherol had migrated into

363 the food simulant from film A and film B, respectively. These amounts correspond to 364 the total original alpha-tocopherol content of the bags, thus a total migration was 365 complexation.

\section{"[insert Figure 2 about here]"} bags weighing $1.2 \mathrm{~g}$ contained approximately $1.94 \mathrm{mg}$ alpha-tocopherol. As the initial concentration in film B found to be $1500 \pm 322 \mathrm{mg} \mathrm{kg}^{-1}$ and the bags weighed $1.0 \mathrm{~g}$, therefore the initial amount of alpha-tocopherol was $1.50 \mathrm{mg}$. observed for both films. It means that $95 \%$ ethanol proved to be a potent extractant and the partition between the polymers and the food simulant was neglectable. This finding is in accordance with the results of Wessling et al. (1998) and Heirlings et al. (2004) for free alpha-tocopherol. It can be also concluded that the partition coefficient of alphatocopherol between the polymer and food simulant was not influenced by the complexation. 
372 Reliable migration predictions require the description of the physical migration process

373 by a correct mathematical equation, i.e. good agreement between predicted values and

374 experimental data. The migration profiles of the two different films were fitted towards 375 equation (2) to estimate the diffusion coefficient (D). It can be concluded that the model

376 fitted the experimental values very well for both types of film. The sum of squares in

377 errors (SSE) between the estimated and measured values was found to be as low as

3780.05 . The calculated values for D were $1.53 \mathrm{E}-11 \mathrm{~cm}^{2} \mathrm{~s}^{-1}$ and $1.68 \mathrm{E}-12 \mathrm{~cm}^{2} \mathrm{~s}^{-1}$ for film A

379 and B, respectively. There is no doubt that this difference is a consequence of the 380 complexation of alpha-tocopherol in beta-cyclodextrin. It should be emphasised, 381 however, that the calculated diffusion coefficient of alpha-tocopherol in film B is only 382 an apparent value. In general the migration of a compound from a polymer into a food 383 or simulant is of a very complex nature depending on several parameters, thus some 384 simplifications are often made. Modelling this mass transfer process usually considers 385 only a single phenomenon, generally the diffusion of the compound, which is then 386 described by a single and constant diffusion coefficient. It is well known, however, that 387 the presence of large amounts of other substances interferes with the diffusion process. 388 Most of the models applied however do not take into account specific molecular 389 interactions (e.g. association-dissociation processes in molecular complexes). In the 390 present study it was expected that the molecular encapsulation in beta-cyclodextrin 391 would also significantly influence the migration of alpha-tocopherol. The release 392 kinetics of a complexed substance depends not merely on diffusion, but also on the ratio

393 between its complexed and uncomplexed fractions, which is governed by the complex 394 association/dissociation equilibrium characterized by the complex stability constant 
$395\left(\mathrm{~K}_{1: 1}\right)$. This thermodynamic equilibrium for beta-cyclodextrin (CD) and alpha-

396 tocopherol (AT) can be described by the following equations.

397

$398 C D+A T \leftrightarrow C D A T$

$399 \quad K_{1: 1}=\frac{[C D A T]}{[C D][A T]}$

400

401 where $\mathrm{K}_{1: 1}$ represents the stability constant of the beta-cyclodextrin/alpha-tocopherol

402 complex, while [CD], [AT] and [CD AT] correspond to the solubility of beta-

403 cyclodextrin, alpha-tocopherol and their complex, respectively. As beta-cyclodextrin is

404 insoluble in $95 \%$ ethanol it can be supposed that it remains in the polymer matrix.

405

406 Regarding alpha-tocopherol a partition can be expected between its complexed and

407 uncomplexed form. However, as complexation is a dynamic and usually reversible

408 process, this partition could only be interpreted for a particular moment: both

409 association and dissociation of the complexes take place at the same time. It is

410 presumable that only molecules being uncomplexed can participate in the migration

411 process. The amount of the uncomplexed alpha-tocopherol at a particular moment

412 depends on the equilibrium described above. Most of the studies of cyclodextrin

413 complex stability have been carried out in aqueous solutions and only a few workers

414 have investigated complex formation in organic solvents (Connors 1997). In general,

415 the decrease of the complex stability is assumed in function of increasing apolar nature

416 of the solvent. This can be explained by the fact, that apolar organic solvents decrease

417 the hydrophobic driving force: namely, apolar guests prefer solvents to semi-apolar 
418 cyclodextrin cavity. Moreover, molecules of the organic solvents can function as

419 competitive guest molecules, thus displacing the primary guests.

420

\section{Conclusions}

422 Complexation by beta-cyclodextrin was found to be an effective tool for controlling the 423 release of alpha-tocopherol from antioxidative active packaging. Complexation had a 424 significant influence on the migration profile and release rate. Migration of complexed 425 antioxidant was rather slow compared to that of free alpha-tocopherol. Depletion of the 426 antioxidant was completed in about 1000 hours compared to about 3500 hours in case 427 of free and complexed alpha-tocopherol, respectively. The slower release rate was 428 proved also by the significant difference between the diffusion coefficients determined 429 by using a mathematical model to describe the release rate numerically. The migration 430 model fitted the experimental values very well. Rather small sum of squares in errors 431 between the estimated and measured values was found. The diffusion coefficient for the 432 complexed alpha-tocopherol was one order of magnitude lower than for the 433 uncomplexed additive. Therefore, it can be stated that a controlled release of alpha434 tocopherol from LDPE packaging films was achieved by inclusion complexation with 435 beta-cyclodextrin.

437 Acknowledgements

438 This work was supported by the Economic Competitiveness Operational Program of 439 Hungary (GVOP 3.1.1). The plastic packaging films were extruded and supplied by 440 Plastline Ltd, Pilisszántó, Hungary. All contributions are gratefully acknowledged. 441 


\section{References}

443 Al-Malaika S, Ashley H, Issenhuth S. 1994. The antioxidant role of $\alpha$-tocopherol in polymers. I. The nature of transformation products of $\alpha$-tocopherol formed during melt processing of LDPE. Journal of Polymer Science Part A: Polymer Chemistry 32: $3099-3113$.

Al-Malaika S, Goodwin C, Issenhuth S and Burdick D. 1999. The antioxidant role of $\alpha-$ tocopherol in polymers II. Melt stabilising effect in polypropylene. Polymer Degradation and Stability 64: 145-156.

Al-Malaika S, Issenhuth S. 2001a. The antioxidant role of vitamin E in polymers. IV. Reaction products of DL- $\alpha$-tocopherol with lead dioxide and with polyolefins. Polymer 42: 2915-2939.

Al-Malaika S, Issenhuth S, Burdick D. 2001b. The antioxidant role of vitamin E in polymers V. Separation of stereoisomers and characterisation of other oxidation products of DL- $\alpha$-tocopherol formed in polyolefins during melt processing. Polymer Degradation and Stability 73: 491-503.

Appendini P, and Hotchkiss JH. 2002. Review of antimicrobial food packaging. Innovative Food Science and Emerging Technologies. 3: 113-126.

Bezemer JM, Radersma R, Grijpma DW, Dijkstra PJ, Feijen J and van Blitterswijk CA. 2000. Zero-order release of lysozyme from poly(ethylene glycol)-poly(butylene terephthalate) matrices. Journal of Controlled Release 64: 179-192.

462 Billingham NC and Garcia-Trabajo P. 1995. The possibilities of microencapsulated 463 antioxidants for polymers. I: a theoretical analysis. Polymer Degradation and Stability 48: 419-426. 
465 Colombo P, Bettini R, Santi P, De Ascentiis A and Peppas NA. 1996. Analysis of the 466 swelling and release mechanisms from drug delivery systems with emphasis on drug solubility and water transport. Journal of Controlled Release 39: 231-237.

Connors KA. 1997. The stability of cyclodextrin complexes in solution. Chemical Reviews 97: 1325-1357.

Crank J. 1975. Mathematics of diffusion. $2^{\text {nd }}$ edition. London: Clarendon Press. p 414.

EC, 2004. Regulation (EC) No 1935/2004 of the European Parliament and of the Council of 27 October 2004 on materials and articles intended to come into contact with food and repealing Directives 80/590/EEC and 89/109/EEC. Official Journal of the European Union L338. 13.11.2004: 4-17.

EEC, 1988. Council Directive No. 89/107/EEC of 21 December 1988 on the 476 approximation of the laws of the Member States concerning food additives authorized for use in foodstuffs intended for human consumption. Official Journal

Garde JA, Catalá R, Gavara R and Hernandez RJ. 2001. Characterizing the migration of 483 of the European Communities L040. 11.02.1989: 27-33.

Floros J, Nielsen P, Farkas J. 2000. Advances in modified atmosphere and active packaging with applications in the dairy industries. Bulletin of the International Dairy Federation 346: 22-28.

Hamdani M, Feigenbaum A, Vergnaud JM. 1997. Prediction of worst case migration 486 from packaging to food using mathematical models. Food Additives and Contaminants 14: 499-506. 
488 Hedges AR, Shieh WJ and Sikorski CT. 1995. Use of cyclodextrins for encapsulation in the use and treatment of food products. In: Risch SJ and Reineccius GA, editors. Encapsulation and controlled release of food ingredients. ACS symposium series No 590. Washington DC: American Chemical Society. 60-71 p.

Heirlings L, Siró I, Devlieghere F, Van Bavel E, Cool P, De Meulenaer B, Vansant EF and Debevere J. 2004. Influence of polymer matrix and adsorption onto silica materials on the migration of alpha-tocopherol into $95 \%$ ethanol from active packaging. Food Additives and Contaminants 11:1125-1136.

Helmroth IE, Dekker M and Hankemeier T. 2002. Influence of solvent absorption on the migration of Irganox 1076 from LDPE. Food Additives and Contaminants 19: 176-183.

Hernandez-Muñoz P, Catala R, Gavara R. 2002. Simple method for the selection of appropriate food stimulant for the evaluation of a specific food/packaging interaction. Food Additives and Contaminants 19:192-200.

502 Kuijpers AJ, Engbers GHM, van Wachem PB, Krijgsveld J, Zaat SAJ, Dankert J and Feijen J. 1998. Controlled delivery of antibacterial proteins from biodegradable matrices. Journal of Controlled Release 53: 235-247.

LaCoste A, Schaich KM, Zumbrunnen D, Yam KL. 2005. Advancing controlled release packaging through smart blending. Packaging Technology and Science 18:77-87.

507 Maisuthisakul P, Suttajit M, Pongsawatmanit R. 2006. Assessment of phenolic content and free-radical scavenging capacity of some Thai indigenous plants. Food Chemistry (article in press)

Miltz J, Hoojjat P, Han JK, Giacin JR, Harte BR and Gray IJ. 1987. The loss of antioxidants from HDPE film and its effect on the shelf life of oatmeal cereal. In: 
512

513

514

515

516

517

518

519

520

521

522

523

524

525

526

527

528

529

530

531

532

533

534

Hotchkiss JH (editor). Chemical Interactions between food and food packaging. ACS symposium series No 365. Washington DC: American Chemical Society. 83-93 p.

Miltz J, Passy N, and Manneheim CH. 1995. Trends and applications of active packaging systems. In: P. Ackermann, M. Jagerstad, and T. Ohlsson (editors). Foods and Packaging Materials-Chemical Interactions. Cambridge, UK: The Royal Society of Chemistry. p 201-210.

Onyeneho SN and Hettiarachchy NS. 1992. Antioxidant activity of durum wheat bran. Journal of Agricultural and Food Chemistry 40: 1496-1500.

Piringer OG. 2000. Transport equations and their solutions. In: Piringer OG and Baner AL, editors. Plastic Packaging Materials for Food. Weinheim: Wiley-VCH. p 183219.

Szejtli J. 1996. Inclusion of guest molecules, selectivity and molecular recognition by cyclodextrins. In: Szejtli J, Osa T, editors. Comprehensive. Supramolecular Chemistry. Oxford: Elsevier. p 189-203.

Vermeiren L, Devlieghere F, van Beest M, de Kruijf N, and Debevere J. 1999. Developments in the active packaging of foods. Trends in Food Science and Technology 10: 77-86.

Wessling C, Nielsen T, Leufven A, and Jägerstad M. 1998: Mobility of $\alpha$-tocopherol and BHT in LDPE in contact with fatty food simulants. Food Additives and Contaminants 15: 709-715.

Wessling C, Nielsen T, Leufven A, and Jägerstad M. 1999. Retention of alpha tocopherol in low-density polyethylene (LDPE) and polypropylene (PP) in contact 
535 with foodstuffs and food simulating liquids. Journal of the Science of Food and $536 \quad$ Agriculture 79: 1635-1641.

537 Wessling C, Nielsen T and Giacin JR. 2000a. Antioxidant ability of BHT- and $\alpha-$ 538 tocopherol-impregnated LDPE film in packaging of oatmeal. Journal of the 539 Science of Food and Agriculture. 81: 194-201.

540 Wessling C, Nielsen T, and Leufven A. 2000b. The influence of $\alpha$-tocopherol 541 concentration on the stability of linoleic acid and the properties of Low-density $542 \quad$ Polyethylene. Packaging Technology and Science 13: 19-28.

543 Wessling C, Nielsen T, and Leufven A. 2000c. Influence of trace metals, acids and 544 ethanol in food-simulating liquids on the retention of $\alpha$-tocopherol in low-density 545 polyethylene film. Food Additives and Contaminants 17: 713-719.

546 Yu L, Haley S, Perret J, Harris M. 2002. Antioxidant properties of hard winter wheat $547 \quad$ extracts. Food Chemistry 78: 457-461. 


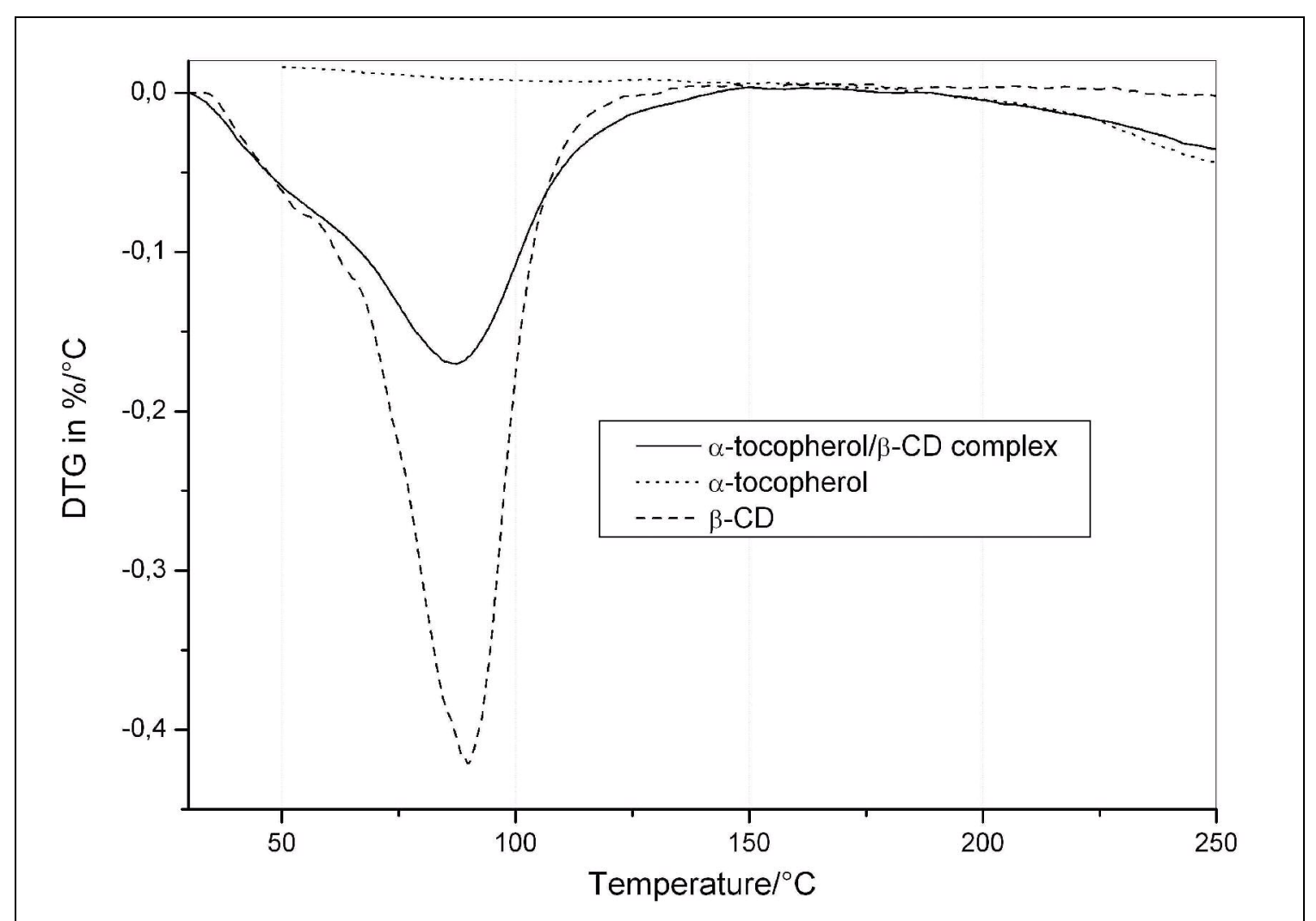

Figure 1 


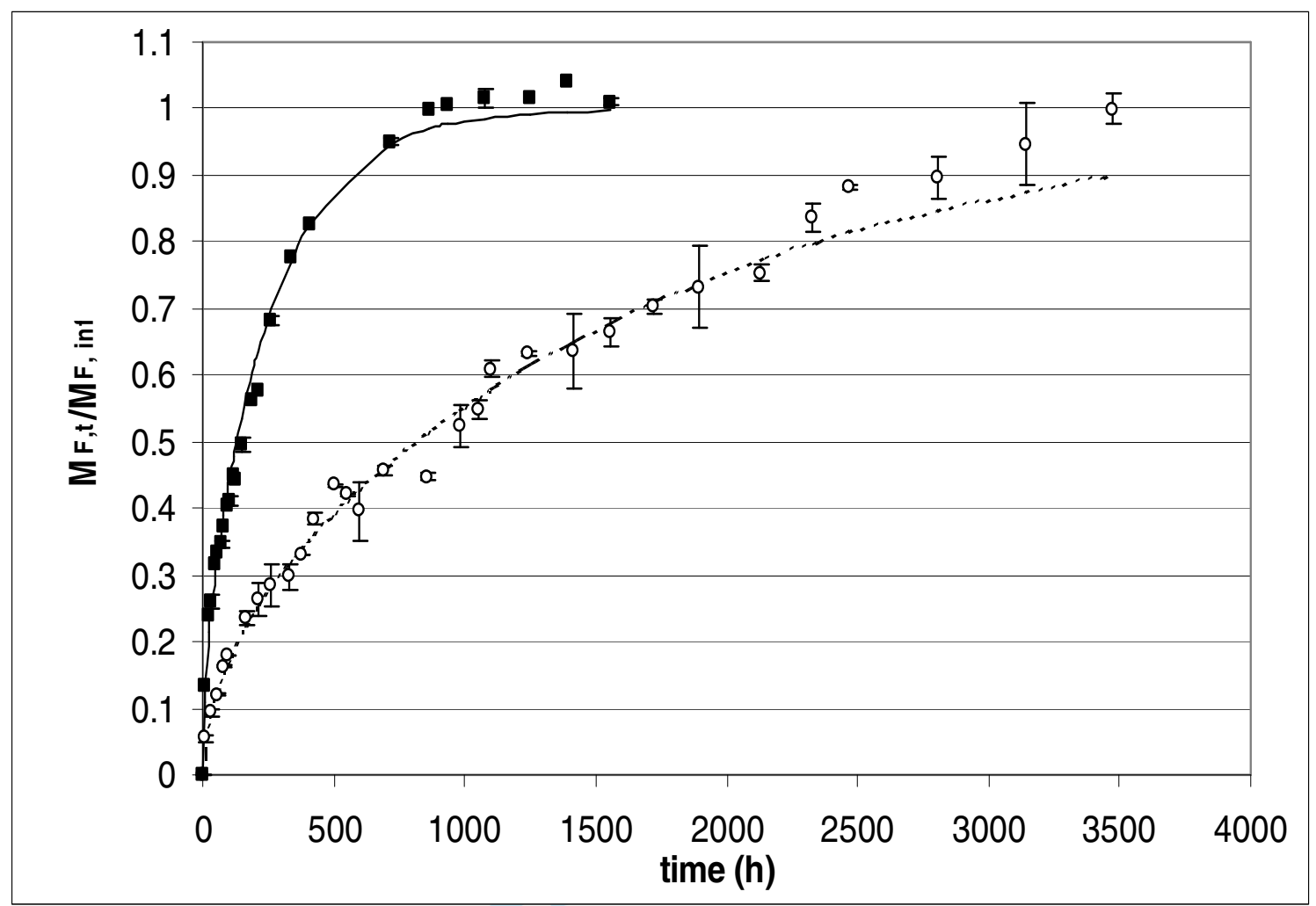

Figure 2 
Figure 1 Differential Thermo-gravimetric curve (DTG) of free alpha-tocopherol (dotted line), beta-cyclodextrin (dashed line) and alpha-tocopherol/beta-cyclodextrin (solid line) complex

Figure 2 Migration of alpha-tocopherol from Film A (匹) and Film B (o) into food fatty food simulant at $7.0 \pm 0.5^{\circ} \mathrm{C}$. Data expressed as the mean of three measurements and error bars shows the standard deviations. Solid line (Film A) and dashed line (Film B) represent the estimated migration of alpha-tocopherol based on a migration model

(Film A: LDPE $2000 \mathrm{mg} \mathrm{kg}^{-1}$ free alpha-tocopherol; Film B: LDPE $2000 \mathrm{mg} \mathrm{kg}^{-1}$ alpha-tocopherol complexed in beta-cyclodextrin) 